\title{
Therapeutics
}

\section{Anti-androgen treatment immediately after surgery for prostate cancer improved survival}

Messing EM, Manola J, Sarosdy M, et al. Immediate hormonal therapy compared with observation after radical prostatectomy and pelvic lymphadenectomy in men with node positive prostate cancer. N Engl J Med 1999 Dec 9;341:1781-8.

QUESTION: In men with node positive prostate cancer, is survival prolonged by starting anti-androgen treatment immediately after surgery rather than delaying it until the appearance of disease progression?

\section{Design}

Randomised \{allocation concealed*\} ${ }^{*}$, unblinded, ${ }^{*}$ controlled trial with median 7.1 years follow up.

\section{Setting}

6 US university centres.

\section{Patients}

98 men (median age 66 y) who had clinically localised prostate cancer ( $\leqslant$ stage T2), had had radical prostatectomy and bilateral pelvic lymphadenectomy within the previous 12 weeks, and had histologically confirmed nodal metastases.

\section{Intervention}

Patients were allocated to anti-androgen treatment with either goserelin, $3.6 \mathrm{mg}$ subcutaneously every 28 days, or bilateral orchiectomy $(n=47)$ or to be followed until evidence existed of disease progression other than newly detectable or rising levels of prostate specific antigen (PSA) $(\mathrm{n}=51)$.

\section{Main outcome measures}

Death, death from prostate cancer, and recurrence.

\section{Main results}

Analysis was by intention to treat. At a median follow up of 7.1 years, more men in the observation group had died from any cause (hazard ratio [HR] 3.0, 95\% CI 1.2 to $7.3 ; \mathrm{p}=0.02$ ) or from prostate cancer (HR 6.2, CI 1.8 to $21.5 ; \mathrm{p}<0.01)$ than had men who received immediate antiandrogen treatment (table). Disease recurrence was greater in the observation group than in the immediate antiandrogen treatment group (HR 12.2, CI 5.1 to 29.1; $\mathrm{p}<0.001)$ (table). Baseline characteristics or type of anti-androgen treatment did not affect survival.

\section{Conclusion}

In men with node positive prostate cancer, starting antiandrogen treatment immediately after surgery rather than delaying it until the appearance of disease progression improved survival.

*See glossary.

†Information provided by author.

Anti-androgen treatment immediately after surgery $v$ observation for node positive prostate cancer at median 7.1 years follow up.

\begin{tabular}{lcccc} 
Outcomes & $\begin{array}{l}\text { Immediate } \\
\text { treatment }\end{array}$ & Observation & RRR (95\% CI) & NNT (CI) \\
Death & $15 \%$ & $35 \%$ & $58 \%(12$ to 81$)$ & 5 (3 to 34$)$ \\
\hline Death from prostate cancer & $6.4 \%$ & $31 \%$ & $80 \%(40$ to 93$)$ & 4 (3 to 10$)$ \\
\hline Any recurrence & $15 \%$ & $82 \%$ & $82 \%(66$ to 91$)$ & 2 (2 to 2$)$ \\
\hline † Abbreviations defined in glossary; RRR, NNT, and Cl calculated from data in article.
\end{tabular}

\section{COMMENTARY}

The study by Messing et al convincingly shows better outcomes for men who, after radical prostatectomy and pelvic lymphadenectomy, are found to have lymph node metastases and are immediately treated with androgen deprivation rather than waiting for disease progression to appear. Such men are at high risk for disease progression, even those with low PSA levels after surgery alone (only $16 \%$ of the control group in this study showed no evidence of disease progression over 7 years). These results are consistent with a trial done in the UK that also showed improved cancer specific survival for men with locally advanced or asymptomatic metastatic disease who were treated with immediate androgen deprivation. ${ }^{1}$

One problem with long trials is that as new technologies appear, the trials' results may be less helpful in practice than originally hoped. Currently, widespread PSA screening has resulted in a "stage shift," with a small percentage of radical prostatectomies now associated with positive nodes.

Most men who are started on androgen deprivation show evidence of residual or recurrent cancer after surgery or radiation treatment solely on the basis of PSA levels. Those with recurrent disease have a better prognosis than node positive patients, with a median time to a positive bone scan of 8 years without treatment. ${ }^{2}$ As a result, competing risks become more of an issue for patients with recurrent disease than for node positive patients. Furthermore, the cumulative effects on health after years or decades of androgen deprivation are only now emerging. These consequences were reported only superficially in this study. Further trials comparing early with delayed androgen deprivation are needed before assuming that early androgen deprivation has a similar risk benefit tradeoff in men who have either early evidence of disease recurrence or prognostic factors at the time of primary treatment that suggest a major risk for future recurrence.

Michael J Barry, MD Massachusetts General Hospital Boston, Massachusetts, USA

1 The Medical Research Council Prostate Cancer Working Party Investigators Group. Immediate versus deferred treatment for advanced prostatic cancer: initial results of the Medical Research Council Trial. Br J Urol 1997;79:235-46.

2 Pound CR, Partin AW, Eisenberger MA, et al. Natural history of progression after PSA elevation following radical prostatectomy. JAMA 1999;281;1591-7.
Sources of funding:

National Institutes of Health and

Department of Health and Human Services.

For correspondence: Dr E M Messing,

University of Rochester, Department of Urology, 601 Elmwood Avenue, Box 656, Rochester, $N Y$ 14642, USA. Fax +1 7164428350 